\title{
CONTINUOUS-CULTURE STUDIES OF INTERACTIONS AMONG HUMAN SKIN-COMMENSAL BACTERIA
}

\author{
P. D. MARSH* AND S. SELWYN \\ Department of Bacteriology, Westminster Medical School, London, SWIP $2 A R$
}

THE study of interactions among skin commensals has been prompted by the recent finding that more than one-fifth of normal persons possess antibiotic-producing bacteria on their skin (Selwyn and Ellis, 1972). The antagonistic effects of a strain of Staphylococcus epidermidis against a variety of bacteria have been investigated both semi-quantitatively on solid media and quantitatively in liquid batch cultures (Marsh and Selwyn, 1977). However, batch cultures permit only short-term growth studies, and the organisms in such a system undergo unrealistically wide changes in population density in comparison with those observed in most in-vivo situations. Studies have therefore now been performed in a chemostat, which provides stable long-term growth conditions.

\section{MATERIALS AND METHODS}

Bacterial strains. These were strain $\mathrm{S}^{+}$, an antibiotic-producing strain of S. epidermidis, biotype 4 (Baird-Parker, 1974); strain $\mathrm{S6}^{-}$, an antibiotic non-producing $S$. epidermidis of biotype 4; and strain M7, a Micrococcus of biotype 7 (Baird-Paker, 1965). All three strains had been isolated from the forehead of one of us (S. S.). Previous studies on solid and in liquid media showed that strain M7 was antagonised by strain $\mathrm{S6}^{+}$but not by strain $\mathrm{S}^{-}{ }^{-}$; the latter was itself unaffected by strain S6+ (Marsh and Selwyn, 1977).

Media. Peptone water was used as growth medium for the continuous cultivation of strains $\mathrm{S6}^{+}, \mathrm{S6}^{-}$and $\mathrm{M} 7$ (both pure and mixed) at two concentrations: $0.1 \%(\mathrm{w} / \mathrm{v})$ for studies at low population levels and $0.5 \%(\mathrm{w} / \mathrm{v})$ for high population levels.

Selective media were developed for strains $\mathrm{S}^{+}, \mathrm{S6}^{-}$and $\mathrm{M} 7$ in accordance with the MICs of various antibiotics for them. These media enabled accurate viable counts of each strain to be made from mixed cultures. The three selective media used were: nutrient agar with bacitracin $1.25 \mu \mathrm{g}$ per $\mathrm{ml}$ and fusidic acid $0.196 \mu \mathrm{g}$ per ml for strain $\mathrm{S6}^{+}$; nutrient agar with bacitracin $1.25 \mu \mathrm{g}$ per ml and benzylpenicillin $0 \cdot 10 \mu \mathrm{g}$ per $\mathrm{ml}$ for strain $\mathrm{S}^{-}$; and nutrient agar with furazolidone $7.5 \mu \mathrm{g}$ per $\mathrm{ml}$ and kanamycin $0.156 \mu \mathrm{g}$ per ml for strain M7.

Chemostat. The design of the simple continuous culture apparatus was based on that of a "Porton-type" chemostat described by Evans, Herbert and Tempest (1970). It had two reservoirs for medium that could be used alternately through a two-way tap, thus allowing the effects of both $0.1 \%$ and $0.5 \%$ peptone water to be observed during the same experiment. The volume of the culture vessel was $100 \mathrm{ml}$, and a water jacket maintained the temperature of the culture at $33^{\circ} \mathrm{C}$. A variable-speed flow-inducer, MRHE 22 (Watson-Marlow Ltd) was used to provide a constant dilution rate of 0.3 per $h$ in all experiments.

Viable counts. Culture fluid for viable counts was removed twice daily from the culture vessel by a sampling device in a port on top of the culture vessel (Marsh, 1975). Colony counts per $\mathrm{ml}$ were made on the appropriate selective media by the method of Miles, Misra and Irwin (1938), and growth curves were constructed. Differences in counts greater than $0.4 \log _{10}$ were significant at the $5 \%$ level.

\section{RESULTS}

Pure cultures of all three strains in $0.5 \%$ peptone water reached steady-state conditions at $10^{7 \cdot 6 \pm 0.1}$ for strain $\mathrm{M} 7,10^{7 \cdot 8 \pm 0.1}$ for strain $\mathrm{S}^{-}$and $10^{7 \cdot 7 \pm 0.2}$ for $\mathrm{S}^{+}$. In $0 \cdot 1 \%$ peptone water the three strains stabilised at a population level of $10^{6 \cdot 2 \pm 0 \cdot 1}$ in pure culture.

Received 5 Nov. 1976; accepted 27 Nov. 1976.

* Present address: MRC Dental Epidemiology Unit, The London Hospital Medical College, London, E1 2AD.

J. MED. MICROBIOL.-VOL. 10 (1977) 
TABLE

Colony counts of antibiotic-producting (strain $\mathrm{S6}^{+}$) and non-producing (strain $\mathrm{S6}^{-}$) staphylococci and indicator micrococcus (strain $\mathrm{M} 7$ ) when grown in pairs or as pure cultures in $0.5 \%$ peptone water

\begin{tabular}{|c|c|c|c|c|}
\hline \multirow{3}{*}{$\begin{array}{c}\text { Time } \\
\text { (days) }\end{array}$} & \multicolumn{4}{|c|}{$\begin{array}{l}\text { Mean } \log _{10} \text { colony counts per } \mathrm{ml} \text { in pairs } \\
\text { (and pure cultures) }\end{array}$} \\
\hline & \multicolumn{2}{|c|}{ Pair 1} & \multicolumn{2}{|c|}{ Pair 2} \\
\hline & Strain $\mathrm{S6}^{-}$ & Strain M7 & Strain $\mathrm{S}^{+}$ & Strain $\mathbf{M} 7$ \\
\hline $\begin{array}{l}0 \\
1 \\
2 \\
3 \\
4 \\
5 \\
6 \\
7 \\
8 \\
9\end{array}$ & 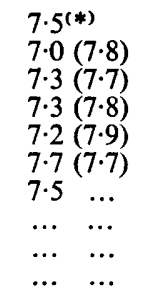 & 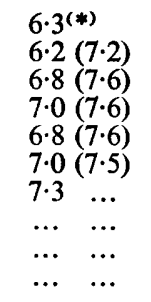 & 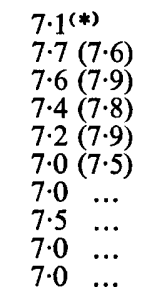 & 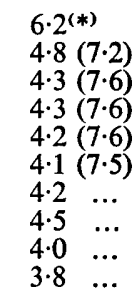 \\
\hline
\end{tabular}

* Started as batch cultures and therefore not comparable with paired cultures until day 1. $\cdots=$ Not done.

The results of growing two strains together in the chemostat in $0.5 \%$ peptone water confirm our previous finding on solid media and in liquid batch cultures that the growth of strain $\mathrm{S6}^{-}$had no effect on that of strain M7. Under similar conditions, strain $\mathrm{S6}^{+}$ inhibited the growth of strain M7 by a factor of $>3 \log _{10}$ (the table). Both in pure and mixed culture the results were not influenced by the inoculum size.

When the three strains were grown together in $0.1 \%$ peptone water, the viable counts were similar to those obtained in pure cultures and no antagonism was detected. However, in $0.5 \%$ peptone water, when strain $\mathrm{S}^{+}{ }^{+}$was inoculated after 2 days, the viable count of strain M7 fell over 200-fold after some delay, while that of strain $\mathrm{S6}^{-}$stayed relatively constant (fig. 1).

The results when all three strains were grown together in mixed culture and the growth medium was changed during the course of the experiment are shown in fig. 2 . In $0 \cdot 1 \%$ peptone water the three strains maintained steady-state conditions with no demonstrable antagonism. When, after 3 days, the inflow was changed to $0.5 \%$ peptone water, strains $\mathrm{S6}^{+}$and $\mathrm{S6}^{-}$responded immediately to the richer medium, and the viable counts of both increased to levels similar to those obtained in pure cultures. However, strain M7 failed to respond to the increased concentration of nutrients; after a small fall, the viable count stayed at a level slightly lower than that in $0.1 \%$ peptone. Nevertheless, strain M7 was able to respond to this change in the medium when grown in mixed culture without strain $\mathrm{S6}^{+}$, although it reached a lower steady-state population than did strain $\mathrm{S6}^{-}$(fig. 3). When, however, strain $\mathrm{S6}^{+}$was introduced after 5 days, the viable count of strain $\mathrm{M} 7$ fell by a factor of $1 \log _{10}$ while that of strain $\mathrm{S6}^{-}$remained constant.

\section{Discussion}

Antagonism of strain M7 was seen only in $0.5 \%$ peptone water, in which viable counts of strain $\mathrm{S}^{+}$reached at least $10^{7 \cdot 0}$; evidently the smaller populations of strain $\mathrm{S}^{+}$in $0.1 \%$ peptone water did not produce inhibitory concentrations of antibiotic. This explanation is supported by assays of the crude inhibitory agent in samples of media examined during 


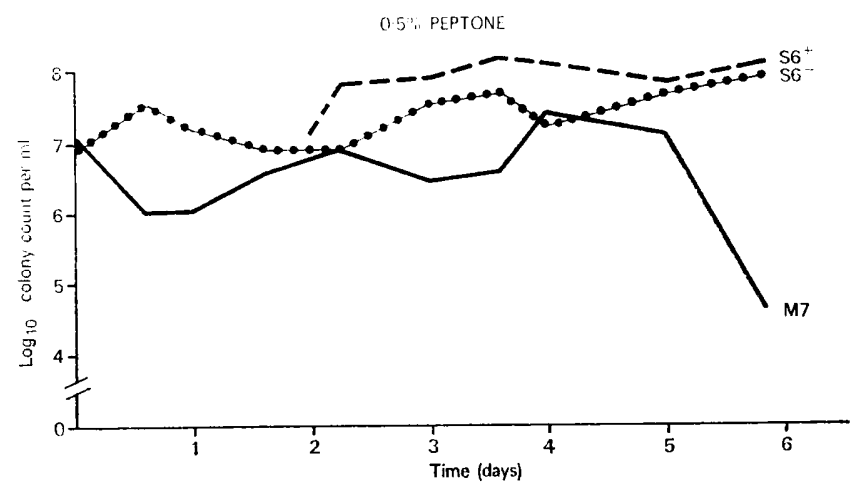

FIG. 1.-Growth in mixed chemostat cultures of strains $\mathrm{S6}^{-}$and $\mathrm{M7}$, with subsequent addition of strain $\mathrm{S}^{+}$, in $0.5 \%$ peptone water.

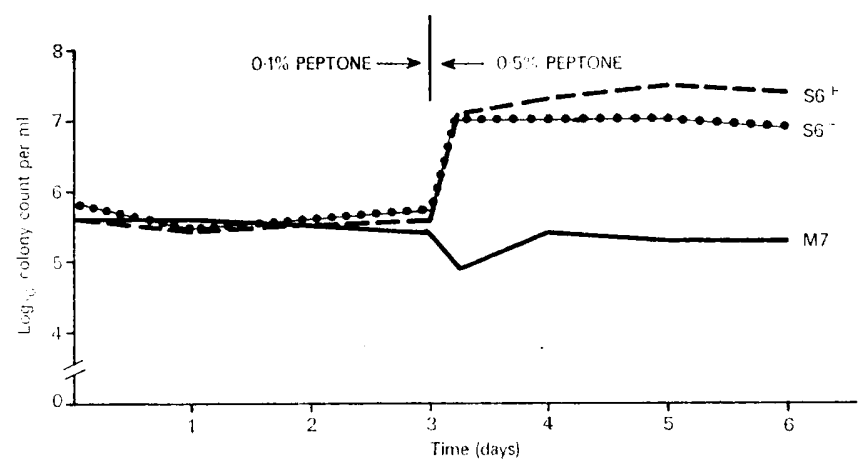

FIG. 2.-Growth in mixed chemostat cultures of strains $\mathrm{S}^{+}, \mathrm{S}^{-}$and $\mathrm{M} 7$ in $0 \cdot 1 \%$ peptone water, and subsequently in $0.5 \%$ peptone water.

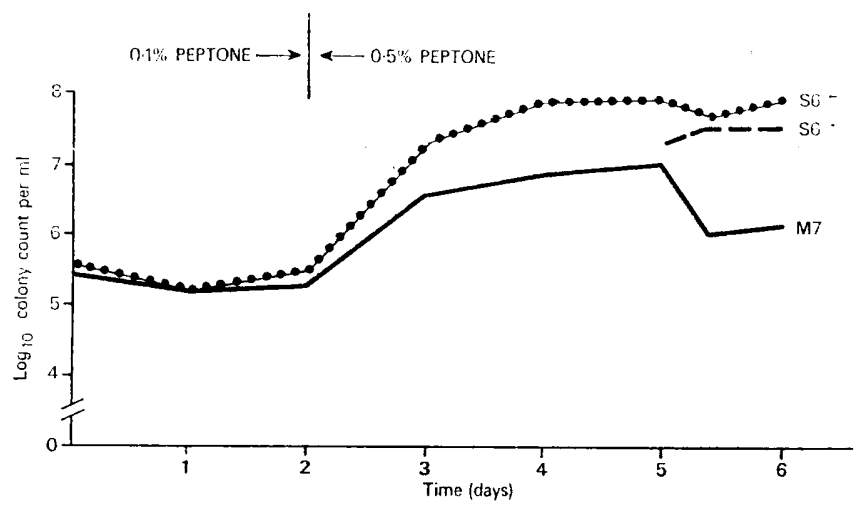

FIG. 3.-Growth in mixed chemostat cultures of strains $\mathrm{S}^{-}$and $\mathrm{M} 7$ first in $0.1 \%$ peptone water, then in $0.5 \%$ peptone water, and finally after the addition of strain $\mathbf{S}^{+}$. 
our previous batch-culture studies (Marsh and Selwyn, 1977), as well as by the effects of changing the growth medium during the course of an experiment (fig. 2).

Antagonism took between $12 \mathrm{~h}$ and 3 days to become manifest in continuous culture. This is considerably longer than we had observed in batch culture, in which "washing-out " of antibiotic does not occur (Marsh and Selwyn, 1977). In all the chemostat experiments, however, the viable count of strain $\mathbf{S 6}^{-}$remained fairly constant under stable conditions, showing that the inhibition of strain M7 was not due to fluctuations in the operation of the culture system.

The micrococci are obligate aerobes and so are sensitive to inadequate aeration of the culture medium. The results obtained in batch cultures (Marsh and Selwyn, 1977), and those given in the table show, however, that oxygen limitation was not responsible for the inhibition of strain M7. When a mixture of strains $\mathrm{S6}^{-}$and $\mathrm{M} 7$ was grown in $0.5 \%$ peptone, both strains reached viable counts approaching those obtained under the same conditions in pure culture. In contrast, when strains $\mathrm{S6}^{+}$and $\mathrm{M} 7$ were grown together under identical conditions, strain M7 was inhibited.

In its original habitat on normal human skin, strain $\mathrm{S}^{+}$was unable to suppress strain M7, and both grew in a relatively steady state with strain S6- (Selwyn, 1975). However, when skin hydration was greatly increased, strain $\mathrm{S6}^{+}$readily exerted an inhibitory effect against strain M7 and other sensitive organisms (Selwyn, Marsh and Sethna, 1976). Under these conditions, skin is comparable to a suitable agar medium, supporting good bacterial growth and production of antibiotic substances without allowing excessive dilution of the latter. This concept is well illustrated when comparing mixed-culture results on solid and in liquid media. Previous work (Marsh and Selwyn, 1977) showed that the bactericidal action of the strain $\mathrm{S}^{+}$inhibitory agent could be readily demonstrated on solid media, but only the extremely sensitive group-D diphtheroid was completely inhibited in liquid batch cultures. Continuous-culture techniques offer many obvious advantages over batch cultures, but suffer from the unavoidable disadvantage, common to all liquid systems, of diffusion and dilution of metabolic products. In agar, high local concentrations can readily reach bactericidal levels, whereas in broth the titres produced by relatively fewer cells dispersed in a comparatively large volume of fluid appear usually to attain only bacteristatic levels.

An improved system is clearly required for the long-term quantitative study of bacterial interrelationships on solid surfaces. This type of system should combine the quantitative steady-state conditions of traditional continuous-culture techniques with a solid surface for the growth of the desired organisms and the retention of microbial products. This would not only be more suitable for investigating antagonisms of the type discussed and more relevant to skin ecology, but would also find applications in the study of other microbial interactions. Such a system is under development and the preliminary results have been reported (Milyani, 1976).

\section{SUMmary}

Chemostat studies were made of an antibiotic-producing Staphylococcus epidermidis strain $\left(\mathrm{S6}^{+}\right)$, a similar, but antibiotic non-producing $S$. epidermidis strain ( $\left.\mathbf{S 6}^{-}\right)$, and a sensitive indicator strain of Micrococcus sp. (M7). Pure and mixed continuous cultures were investigated at low population levels (in $0.1 \%$ peptone water) and at higher levels (in $0.5 \%$ peptone water). Strain $\mathrm{S}^{+}$antagonised the growth of strain $\mathrm{M} 7$ when its colony count was maintained above $10^{7 \cdot 0}$ per $\mathrm{ml}$, while strain $\mathrm{S6}^{-}$remained unaffected.

\section{REFERENCES}

BaIrd-Parker, A. C. 1965. Staphylococci and their classification. Ann. N.Y. Acad. Sci., $128,4$.

BAIRD-Parker, A. C. 1974. The basis for the present classification of staphylococci and micrococci. Ann. N.Y. Acad. Sci., 236, 7. 
MARSH, P. D. 1975. In vitro studies of antagonism among human skin bacteria. $\mathrm{PhD}$ Thesis, University of London.

Marsh, P. D. AND SelWYN, S. 1977. Studies on antagonism between human skin bacteria. J. med. Microbiol., 10, 161.

Miles, A. A., MisRa, S. S. AND IRwin, J. O. 1938. The estimation of the bactericidal power of the blood. J. Hyg., Camb., 38, 732.

Evans, C. G. T., Herbert, D. AND Tempest, D. W. 1970. The continuous cultivation of micro-organisms. 2. Construction of a chemostat. In Methods in microbiology, vol. 2, edited by J. R. Norris and D. W. Robbins, London, p. 277.

MilyaNI, R. M. 1976. Studies on interactions of human skin micro-organisms on solid surfaces. PhD Thesis, University of London.

SELWYN, S. 1975. Natural antibiosis as a primary defence against infection. Br. J. Derm., 93, 487.

SelwyN, S. AND Ellis, H. 1972. Skin bacteria and skin disinfection reconsidered. Br. med. $J ., 1,136$.

Selwyn, S., Marsh, P. D. and Sethna, T. N. 1976. In vitro and in vivo studies on antibiotics from skin Micrococcaceae. In Chemotherapy, vol. 5 , edited by J. D. Williams and A. M. Geddes, New York and London, p. 391. 